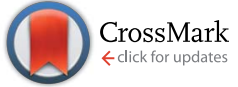

Cite this: RSC Adv., 2017, 7, 15201

Received 4th February 2017

Accepted 22nd February 2017

DOI: $10.1039 / \mathrm{c} 7 \mathrm{ra01426 \textrm {k }}$

rsc.li/rsc-advances

\section{Enhanced photoelectrochemical performance of tungsten oxide film by bifunctional $\mathrm{Au}$ nanoparticles $\uparrow$}

\author{
Yueqi Kong, ${ }^{\text {ab }}$ Honggang Sun, ${ }^{\text {a }}$ Weiliu Fan, ${ }^{\mathrm{b}}$ Li Wang, ${ }^{\mathrm{a}}$ Hongkai Zhao, ${ }^{\mathrm{b}}$ Xian Zhao*b \\ and Shengzhong Yuan ${ }^{c}$
}

\begin{abstract}
In the present study, Au nanoparticles were used to improve the photoelectrochemical performance of tungsten oxide film. Our study indicated that the surface plasmon resonance (SPR) of the Au nanoparticles at about $560 \mathrm{~nm}$ wavelength extended the light adsorption of the $\mathrm{WO}_{3}$ film. Mott-Schottky measurements and theoretical calculations determined that an inner electric field is built at the $\mathrm{Au} / \mathrm{WO}_{3}$ interface through electronic transfer from $\mathrm{Au}$ to $\mathrm{WO}_{3}$. The measured photocurrent density and quantum efficiency results indicated that the synergistic effect of SPR and the inner electric field improved the PEC performance of the $\mathrm{Au} / \mathrm{WO}_{3}$ photoelectrodes. However, the load of Au nanoparticles should be carefully considered due to the introduction of the surface recombined centers. The present study provides a reasonable understanding of the effects of the Au nanoparticles on the PEC performance of the $\mathrm{WO}_{3}$ film.
\end{abstract}

\section{Introduction}

Photoelectrochemical (PEC) water splitting for hydrogen and oxygen production has been paid considerable attention as it is a promising technology to alleviate both the energy crisis and environmental issues. ${ }^{1-5}$ For the PEC system, the properties of photoelectrode materials play an important role on the system performance. In recent years, the photoelectrode consisting of nanostructured n-type transition metal oxide has attracted increasing research interest due to the advantages of chemical stability, efficient light absorption, and ease of fabrication. ${ }^{6-11}$ Herein, tungsten oxide $\left(\mathrm{WO}_{3}\right)$ has been seen as a promising photoelectrode material for the PEC water oxidation system due to its $2.6-2.8 \mathrm{eV}$ band gap and photostability in water. ${ }^{\mathbf{1 2 - 1 5}}$ Furthermore, $\mathrm{WO}_{3}$ can also provide enough overpotential for the crucial half reaction of oxygen evolution due to its favorable valence position (which is approximately $3 \mathrm{~V}$ versus NHE). Recently, $\mathrm{Ma}$ and coworkers reported that a mesoporous $\mathrm{WO}_{3}$ photoanode with a dual oxygen and tungsten vacanciescontaining overlayer could greatly enhance the PEC activity

${ }^{a}$ School of Mechanical, Electrical \& Information Engineering, Shandong University, Weihai, 264209, China. E-mail: sunhg@sdu.edu.cn; Fax: +86-531-88364864; Tel: +86-531-88366330

${ }^{b}$ State Key Laboratory of Crystal Materials, Shandong University, Jinan, 250100, China.E-mail: zhaoxian@sdu.edu.cn

${ }^{c}$ Supercomputing Center, Shandong University, Weihai, 264509, China

$\dagger$ Electronic supplementary information (ESI) available: The XRD patterns of the $\mathrm{Au} / \mathrm{WO}_{3}-X$ samples, the top-view images of the bare FTO glass with and without crystal seed, the HRTEM of $\mathrm{Au} / \mathrm{WO}_{3}-2 \mathrm{~h}$ and $\mathrm{Au} / \mathrm{WO}_{3}-4 \mathrm{~h}$ samples, and the surface structures and potentials for the $\mathrm{WO}_{3}$ (010) faces with two, three and four Au atoms. See DOI: 10.1039/c7ra01426k for water oxidation, which was attributed to alleviating charge recombination at the electrode/electrolyte interface. ${ }^{16}$ Wang's group successfully prepared $\mathrm{WO}_{3}$ nanoplate arrays on FTO glass substrates by tuning the hydrothermal conditions, which presented the highest photocurrent density for the bare $\mathrm{WO}_{3}$ photoanode without any cocatalysts or sacrificial reagents. ${ }^{17}$

Nevertheless, $\mathrm{WO}_{3}$ still suffers from some inadequacies, such as the rapid electron-hole recombination, lower reducibility of conduction band electrons, and limited response in most of the visible light region. To overcome these issues, various endeavors have been applied by controlling the nanostructure, doping other elements, constructing heterojunction, and loading cocatalysts. ${ }^{18-22}$ Ding et al. prepared onedimensional nanostructured $\mathrm{WO}_{3}$ by a flame vapor deposition process, which achieved a maximum IPCE efficiency of $45.8 \%$ at $410 \mathrm{~nm}$ through controlling the size of the $\mathrm{WO}_{3}$ nanostructure. ${ }^{12}$ Yang and coworkers used Fe-doping to enhance the PEC performance of the $\mathrm{WO}_{3}$ photoanode, suggesting that this enhancement was related to doping-enhanced charge carrier density. ${ }^{23}$ Bard's group demonstrated that the efficient heterojunction formed on the interface of the $\mathrm{ZnWO}_{4} / \mathrm{WO}_{3}$ composite induced an increased PEC activity for water oxidation under both UV and visible illumination. ${ }^{24}$ In general, noble metals (such as Pt, Au, etc.) and some metal oxides (such as $\mathrm{IrO}_{2}, \mathrm{RuO}_{2}$, etc.) can act as the water splitting cocatalysts to improve the PEC performance of semiconductor based materials..$^{25-30} \mathrm{Pt}$ is usually used as a suitable hydrogen evolution cocatalyst. Bao et al. obtained a considerably high quantum yield (about 60.34\%) when 3-5 nm Pt nanocrystals were loaded as cocatalysts onto CdS. ${ }^{26}$ Yang et al. fabricated a $\mathrm{HfO}_{2}$ passivation layer on the $\mathrm{WO}_{3}$ surface using a dip-coating method, which 
improved the $\mathrm{WO}_{3}$ PEC performance by suppressing the interfacial recombination of electrons and holes. Among them, Au nanoparticles have been focused on and used to extend the light response region due to their surface plasmon resonance $(\mathrm{SPR})^{31,32}$ when coupled with appropriate materials. ${ }^{33-35} \mathrm{TiO}_{2}$ decorated by $\mathrm{Au}$ nanoparticles showed an enhanced PEC performance due to the increased optical absorption associated with the SPR effect. Wu's group noted that the Au nanoparticles in the $\mathrm{CdS}-\mathrm{Au}-\mathrm{TiO}_{2}$ system not only acted as a photosensitizer extending the light response wavelength from 525 to $725 \mathrm{~nm}$ but also promoted the interfacial charge transfer. ${ }^{33}$ Two effects of the loaded Au nanoparticles, both the surface catalysis and the optical functions, were also observed on the $\mathrm{CeO}_{2}$ surface to determine the final photocatalytic performance. ${ }^{36}$ Therefore, a positive role of the $\mathrm{Au}$ nanoparticles on the $\mathrm{WO}_{3}$ photoelectrode can be expected for improving the PEC performance.

Herein, we report a facile hydrothermal method for in situ preparing $\mathrm{WO}_{3}$ films, and successfully obtaining a series of $\mathrm{Au}$ modified $\mathrm{WO}_{3}$ photoanodes by an immersion-calcination method. We characterized the PEC performance for all the samples under both simulated sunlight and visible light irradiation. DFT calculations together with experimental studies were employed to determine the optimal loading amount of $\mathrm{Au}$ nanoparticles, which revealed that the enhanced PEC performance is attributed to the two effects of the loaded Au nanoparticles. Our study takes the bifunctional roles of $\mathrm{Au}$ nanoparticles into consideration simultaneously, and thus can provide a new insight in designing different metal-semiconductor systems for PEC water oxidation.

\section{Experimental}

\subsection{Preparation of $\mathrm{WO}_{3}$ crystal seeds}

All reagents were of analytical grade and used as received without further purification. The $\mathrm{WO}_{3}$ film was fabricated with pre-seeding. In a typical procedure, $3.299 \mathrm{~g}$ of $\mathrm{Na}_{2} \mathrm{WO}_{4} \cdot 2 \mathrm{H}_{2} \mathrm{O}$ was dissolved in $50 \mathrm{~mL}$ deionized water, and the abovementioned solution was vigorously stirred for $10 \mathrm{~min}$. Then, 30 $\mathrm{mL}$ of $3 \mathrm{M} \mathrm{HCl}$ solution was added until no more faint yellow precipitate was formed. The yellow precipitate was collected by centrifugation and washed with deionized water. After that, the precipitate was dissolved into $2 \mathrm{~mL} \mathrm{H}_{2} \mathrm{O}_{2}$ solution to obtain a yellow transparent sol, which was used as the $\mathrm{WO}_{3}$ crystal seed precursor. The as-prepared $\mathrm{WO}_{3}$ crystal seed precursor was then spun coated onto fluorine-doped tin oxide (FTO) glasses (with a size of $3 \times 3.3 \mathrm{~cm}^{2}$ and a resistance of $7 \mathrm{ohm}$ ), which were ultrasonically washed beforehand by deionized water, acetone, and isopropyl alcohol in sequence. Finally, all the spin coated substrates were calcined at $523 \mathrm{~K}$ for $1 \mathrm{~h}$.

\subsection{Preparation of $\mathrm{WO}_{3}$ film}

$1.1547 \mathrm{~g} \mathrm{Na} \mathrm{WO}_{4} \cdot 2 \mathrm{H}_{2} \mathrm{O}$ and $2.0453 \mathrm{~g} \mathrm{NaCl}$ were dissolved into $70 \mathrm{~mL}$ deionized water and the abovementioned solution was vigorously stirred for $10 \mathrm{~min}$. Then, the $\mathrm{pH}$ value of the solution was adjusted to 1.70 by drop-wise adding of $3 \mathrm{M} \mathrm{HCl}$ solution under constant stirring. The as-prepared solution was transferred into a $100 \mathrm{~mL}$ Teflon-lined stainless-steel autoclave and was the precursor for $\mathrm{WO}_{3}$ film growth. The FTO glass substrate coated by $\mathrm{WO}_{3}$ crystal seeds was placed at an incline against the internal wall of the Teflon-lined stainless-steel autoclave, which was sealed and maintained at $413 \mathrm{~K}$ for $4 \mathrm{~h}$. The as-prepared $\mathrm{WO}_{3}$ film was rinsed with deionized water and alcohol in sequence and dried at $333 \mathrm{~K}$ for $1 \mathrm{~h}$. Then, the $\mathrm{WO}_{3}$ film was treated in atmosphere at $523 \mathrm{~K}$ for $2 \mathrm{~h}$.

\subsection{Preparation of $\mathrm{Au}$ nanoparticles modified $\mathrm{WO}_{3}$ film}

$5 \mathrm{M} \mathrm{HAuCl}_{4}$ solutions were prepared with high purity water at room temperature, and then the $\mathrm{pH}$ value of the abovementioned $\mathrm{HAuCl}_{4}$ solution was adjusted to 4.5 with $5 \mathrm{M} \mathrm{NaOH}$ solution. The $\mathrm{WO}_{3}$ film prepared as 2.2 was immersed into the $\mathrm{HAuCl}_{4}$ solution $(\mathrm{pH} 4.5)$ to form $\left[\mathrm{AuCl}(\mathrm{OH})_{3}\right]^{-}$complex on $\mathrm{WO}_{3}$ surface, followed by calcination at $523 \mathrm{~K}$ for $2 \mathrm{~h}$ to grow $\mathrm{Au}$ nanoparticles. ${ }^{37}$ For the purpose of obtaining a series of $\mathrm{Au}$ decorated $\mathrm{WO}_{3}$ film samples with different loading amounts, the immersion time was increased from $15 \mathrm{~min}$ to $4 \mathrm{~h}$. The asprepared $\mathrm{Au}$ modified $\mathrm{WO}_{3}$ films are denoted as $\mathrm{Au} / \mathrm{WO}_{3}-X(X$ represents the immersing time) in this study.

\subsection{Characterization}

Powder X-ray diffraction (XRD) patterns were obtained on a D8 Advanced X-ray diffractometer (Bruker Germany), using $\mathrm{Cu} \mathrm{K} \alpha$ radiation at a scan rate of $0.02^{\circ} 2 \theta \mathrm{s}^{-1}$. Scanning electron microscopy (SEM) was carried out using an S-4800 field emission SEM (FESEM, Hitachi, Japan) with an accelerating voltage of $5 \mathrm{kV}$. High-resolution transmission electron microscopy (HRTEM) analysis was conducted with the use of a JEM 2100 microscope at an accelerating voltage of $200 \mathrm{kV}$. X-ray photoelectron spectroscopy (XPS) measurements were performed on an ESCALAB 250 spectrometer equipped with an $\mathrm{Al} \mathrm{K \alpha}$ source. All the binding energies were referenced to the C1s peak at $284.8 \mathrm{eV}$ of the surface adventitious carbon. Ultraviolet visible (UV-vis) diffuse reflectance spectra were recorded using a UV-vis spectrophotometer (Shimadzu UV-2550, Japan).

\subsection{Photoelectrochemical measurements}

The photoelectrochemical measurements were carried out by a workstation with a standard three electrode system, in which three electrodes were composed of the as-prepared $\mathrm{WO}_{3}$ film (with and without $\mathrm{Au}$ nanoparticles) samples as the working electrode, a Pt foil as the counter electrode and $\mathrm{Ag} / \mathrm{AgCl}$ (saturated $\mathrm{KCl}$ ) as the reference electrode. The electrolyte was $0.5 \mathrm{M}$ $\mathrm{Na}_{2} \mathrm{SO}_{4}$ aqueous solution, and it was bubbled with nitrogen for 30 min under vigorous stirring before measurement. A $300 \mathrm{~W}$ Xe lamp (PLS-SXE300C, Beijing Trusttech Co., Ltd) was employed as the light source, and it was equipped with band-pass or cutoff filters to provide the required light irradiation. The photocurrent density with light on and off was measured by $I-t$ curves at open circuit potential. Mott-Schottky curves were measured with an AC potential frequency of $1 \mathrm{kHz}$ under dark conditions. The electrochemical impedance spectroscopy (EIS) was measured in the frequency range from $10^{5}$ to $10^{-1} \mathrm{~Hz}$ under simulated sunlight irradiation. Moreover, the incident-photon- 
to-current-conversion efficiency (IPCE) was performed in the same three-electrode system at a zero bias versus $\mathrm{Ag} / \mathrm{AgCl}$ using an electrochemical workstation.

\section{Results and discussion}

\subsection{Material characterization}

The crystalline phases of the as-prepared $\mathrm{WO}_{3}$ film were determined from the XRD patterns. The XRD pattern of the FTO substrate is given in Fig. 1a, which is assigned to tetragonal $\mathrm{SnO}_{2}$ (JCPDS no. 41-1445). Fig. $1 \mathrm{~b}$ gives the XRD patterns of the $\mathrm{WO}_{3}$ film on the FTO substrate, in which the characteristic peaks are assigned to hexagonal $\mathrm{WO}_{3} \cdot 0.33 \mathrm{H}_{2} \mathrm{O}$ (JCPDS no. 351001). As shown in Fig. 1c, no impurity peaks and phase changes were observed after treating the film at $523 \mathrm{~K}$. The strengthened peaks of the $\mathrm{WO}_{3}$ film indicated that the hightemperature annealing improved the $\mathrm{WO}_{3}$ crystallinity. The $\mathrm{Au} / \mathrm{WO}_{3}-X$ samples were also characterized by $\mathrm{XRD}$, as shown in the ESI (Fig. S1 $\dagger$ ). All samples presented negligible changes compared with the bare $\mathrm{WO}_{3}$ film, which we attributed to trace amounts of Au loading.

Fig. 2 shows the SEM of the as-prepared $\mathrm{WO}_{3}$ film before and after calcination at $523 \mathrm{~K}$. As shown in Fig. 2a, the $\mathrm{WO}_{3}$ film mainly consisted of several block-like particles with $0.5-2 \mu \mathrm{m}$ sizes after the hydrothermal process. Some nanorods were found to be dispersed on the substrate, which is consistent with the nanorods of the $\mathrm{WO}_{3}$ crystal seed layer. Fig. $2 \mathrm{~b}$ shows that the particles mainly consisted of bundled nanorods with about $30 \mathrm{~nm}$ diameter. The nanorod-like $\mathrm{WO}_{3}$ morphology is in agreement with the previous results under the same experimental conditions. ${ }^{38}$ Fig. $2 \mathrm{c}$ and d present the morphology of the $\mathrm{WO}_{3}$ film after calcination, wherein more block-like particles on the substrate can be observed. Furthermore, as shown in Fig. $2 \mathrm{e}$ and $\mathrm{f}$, the $560 \mathrm{~nm}$ thickness $\mathrm{WO}_{3}$ film with hightemperature treatment is much thicker than the $360 \mathrm{~nm}$ untreated film. The observation indicates that the high-

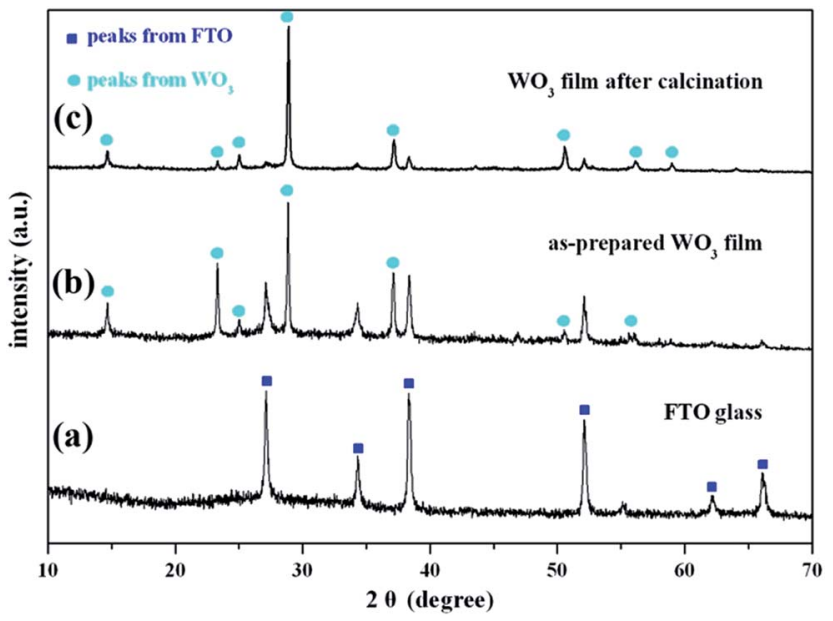

Fig. 1 X-ray diffraction (XRD) patterns of (a) FTO substrate, asprepared $\mathrm{WO}_{3}$ film samples (b) before and (c) after calcination at $523 \mathrm{~K}$ for $1 \mathrm{~h}$ in air. temperature treatment promoted the growth and assembly of $\mathrm{WO}_{3}$ nanorods, which is in agreement with the improved $\mathrm{WO}_{3}$ film crystallinity from the XRD analysis.

Based on the abovementioned analysis, a three-stage growth technique of the $\mathrm{WO}_{3}$ film is proposed and illustrated in Fig. 3 . First, peroxopolytungstic acid (PTA) is prepared by a sol-gel method, and then it is spin-coated onto the clean FTO substrate. The $\mathrm{WO}_{3}$ crystal seed layer with some tiny nanorods is formed by the decomposition of PTA under high-temperature treatment, as shown in Fig. S2. $\dagger$ Second, the crystal seed layer acts as nucleation sites for the $\mathrm{WO}_{3}$ particles to grow in the hydrothermal process. Over time, the initial nanorods gradually aggregate to form broccoli-like structures, and then the $\mathrm{WO}_{3}$ film is formed on the substrate. It is suggested that the precursor condition in the hydrothermal process plays an important role in the $\mathrm{WO}_{3}$ crystal phase and morphology. ${ }^{39}$ Third, $\mathrm{WO}_{3}$ nanorods further grow and aggregate by the hightemperature treatment. In the process, the continuation of the Ostwald ripening induces increased thickness and improved $\mathrm{WO}_{3}$ film crystallinity. The changes promote their electrical contact to the underlying FTO electrode.

The $\mathrm{WO}_{3}$ films are then immersed in the $\mathrm{Au}$ precursor solution, followed by calcination at $523 \mathrm{~K}$ to load $\mathrm{Au}$ nanoparticles. Fig. $4 \mathrm{a}$ and $\mathrm{b}$ give the SEM images of the $\mathrm{Au} / \mathrm{WO}_{3}-1 \mathrm{~h}$ sample, which show a similar morphology to the bare $\mathrm{WO}_{3}$ film. It should be noted that some nanoparticles were distributed on the $\mathrm{WO}_{3}$ film with $15-30 \mathrm{~nm}$ size. As shown in Fig. $4 \mathrm{c}$ and d, the HRTEM image taken at the interface of the nanoparticle and the $\mathrm{WO}_{3}$ nanorods clearly reveals two distinct sets of lattice fringes. The nanoparticle presented an interplanar spacing of $0.24 \mathrm{~nm}$, which is indexed to the $\mathrm{Au}$ (111) plane. The interplanar spacing of $0.38 \mathrm{~nm}$ corresponds to the hexagonal $\mathrm{WO}_{3}$ (0001) plane, which indicates the $\langle 0001\rangle$ growth orientation of the $\mathrm{WO}_{3}$ nanorod. The measured diameters of the Au nanoparticle and the $\mathrm{WO}_{3}$ nanorods were about $25 \mathrm{~nm}$ and $30 \mathrm{~nm}$, respectively. In fact, no noticeable changes were observed for the size and shape of the $\mathrm{Au}$ nanoparticles with increased immersion time, as shown in Fig. S3, $\dagger$ which is in agreement with previous study. ${ }^{37}$ The good interface is in favor of the interaction between the $\mathrm{Au}$ nanoparticles and the $\mathrm{WO}_{3}$ nanorods.

Fig. 5 gives the main surface chemical composition of the bare $\mathrm{WO}_{3}$ and $\mathrm{Au} / \mathrm{WO}_{3}-1 \mathrm{~h}$ films investigated by the XPS technique. As shown in Fig. $5 \mathrm{a}$ and $\mathrm{b}$, the peaks have been divided into two different peaks ( $\mathrm{W}_{4} \mathrm{f}_{5 / 2}$ and $\mathrm{W} 4 \mathrm{f}_{7 / 2}$ ), and each $\mathrm{W} 4 \mathrm{f}$ peak contains two oxidation states: $\mathrm{W}^{6+}$ with binding energies of 35.45 and $37.58 \mathrm{eV}$, and $\mathrm{W}^{5+}$ with binding energies of 34.90 and $37.05 \mathrm{eV}^{40,41}$ The calculated $\mathrm{W}^{5+} / \mathrm{W}^{6+}$ ratios are about $3.24 \%$ and $8.39 \%$ for the bare $\mathrm{WO}_{3}$ and $\mathrm{Au} / \mathrm{WO}_{3}-1 \mathrm{~h}$ films, respectively. Fig. $5 \mathrm{c}$ and $\mathrm{d}$ show the O1s core level spectra, in which the peak at $530.5 \mathrm{eV}$ is ascribed to the lattice oxygen, while the peak at $532.0 \mathrm{eV}$ is ascribed to oxygen vacancy and $\mathrm{OH}$ group adsorbed on the vacancy sites. ${ }^{42-44}$ Stronger vacancy states for the $\mathrm{Au} / \mathrm{WO}_{3}$ $1 \mathrm{~h}$ film were observed. Two reasons contribute to this observation: one is the interaction between Au nanoparticles and the surface oxygen of $\mathrm{WO}_{3}$, and the other is the remnant -OH from $\left[\mathrm{AuCl}(\mathrm{OH})_{3}\right]^{-}$compound. The Au XPS spectrum, as shown in Fig. 5e, gives the characteristic peaks ( $\left(\mathrm{uuff}_{5 / 2}\right.$ and $\left.\mathrm{Au} 4 \mathrm{f}_{7 / 2}\right)$. The 

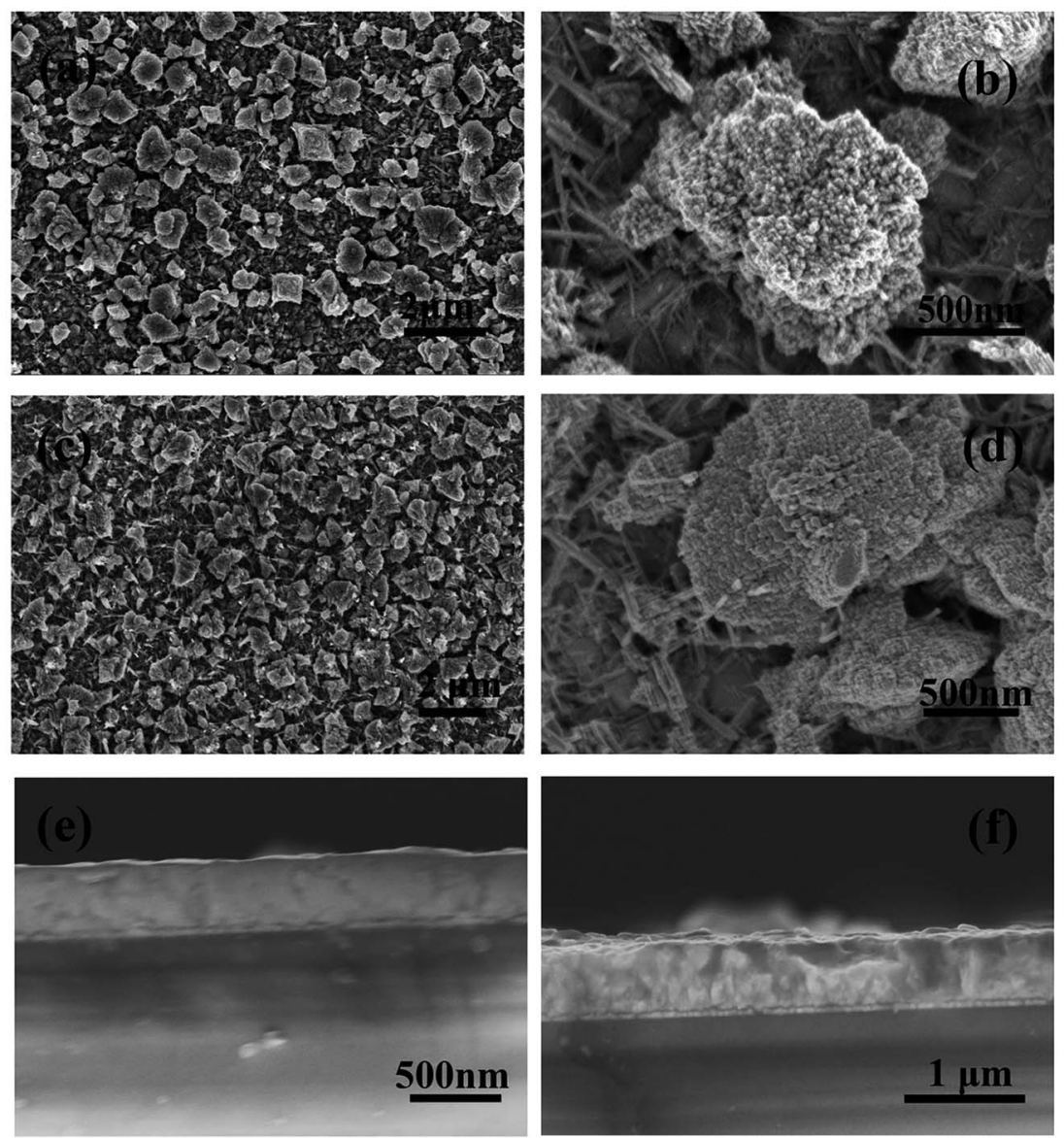

Fig. 2 Top-view SEM images of $\mathrm{WO}_{3}$ film before $(\mathrm{a}$ and b) and after ( $\mathrm{c}$ and d) calcination at $523 \mathrm{~K}$, and cross-section SEM images of WO 3 film before (e) and after ( $f$ ) calcination at $523 \mathrm{~K}$.

peak with binding energy of $83.7 \mathrm{eV}$ is attributed to $\mathrm{Au}^{0}$ states, and the peak with binding energy of $84.4 \mathrm{eV}$ is attributed to $\mathrm{Au}^{+}$ states. ${ }^{41,45}$ The formation of $\mathrm{Au}^{+}$states suggests that some holes were left at the $\mathrm{Au} / \mathrm{WO}_{3}$ interface through the electronic transfer from $\mathrm{Au}$ to $\mathrm{WO}_{3}$. The process will influence the properties of the $\mathrm{Au} / \mathrm{WO}_{3}$ photoelectrode, as discussed below. Moreover, the ratios of $\mathrm{Au} / \mathrm{W}$ on the $\mathrm{Au} / \mathrm{WO}_{3}-X$ surfaces using XPS analysis are listed in Table 1, which shows an increasing Au amount as the immersion time is increased.

\subsection{Photoelectrochemical performance}

With the three-electrode system mentioned above, we studied the photocurrents of the $\mathrm{WO}_{3}$ photoelectrodes as a function of $\mathrm{Au}$ loading amount and compared them to those of the bare $\mathrm{WO}_{3}$ film. As shown in Fig. 6a and b, eliminating the effect of dark current, the simulated sun- and visible-light photocurrent densities of the bare $\mathrm{WO}_{3}$ film were about 5.1 and $0.02 \mu \mathrm{A}$ $\mathrm{cm}^{-2}$, respectively. All the $\mathrm{Au} / \mathrm{WO}_{3}-X$ photoelectrodes showed a higher photocurrent density, as listed in Table 2. The results indicated that the loaded $\mathrm{Au}$ nanoparticles were favorable for improving the PEC performance. The $\mathrm{Au} / \mathrm{WO}_{3}-1 \mathrm{~h}$ photoelectrode presents the highest photocurrent densities of about 21.7 and $1.1 \mu \mathrm{A} \mathrm{cm}^{-2}$.
Fig. 6c shows the UV-vis absorption spectra obtained from the $\mathrm{WO}_{3}$ films in the absence and presence of Au nanoparticles. The bare $\mathrm{WO}_{3}$ film displays an absorption edge at around $420 \mathrm{~nm}$, which matches the band gap of hexagonal tungsten trioxide. The broad and weak absorption region beyond $700 \mathrm{~nm}$ is assigned to the effect of oxygen vacancy. ${ }^{46,47}$ Although there are almost no changes of the host absorption edge, the presence of $\mathrm{Au}$ nanoparticles loaded on the $\mathrm{WO}_{3}$ films extended the absorption range up to $700 \mathrm{~nm}$. The absorption band centered at $560 \mathrm{~nm}$ corresponds to the surface plasmon resonance (SPR) of the Au nanoparticles. The SPR peak is correlated with the size, shape, and the surrounding environment of the Au nanoparticle. ${ }^{48}$ Although the center of the SPR peak of $10 \mathrm{~nm} \mathrm{Au}$ nanospheres in an aqueous solution is typically at $520 \mathrm{~nm}$, the SPR peak would redshift to $560 \mathrm{~nm}$ when the Au nanoparticles were deposited on the $\mathrm{WO}_{3}$ surface. ${ }^{49}$ The redshift was also observed in the $\mathrm{Au} / \mathrm{TiO}_{2}$ system, where the size and shape of the $\mathrm{Au}$ nanoparticle are similar to those in the present study. As shown in Fig. 6d, the photocurrent density of the $\mathrm{Au} / \mathrm{WO}_{3}-1 \mathrm{~h}$ photoelectrode was about $0.05 \mu \mathrm{A} \mathrm{cm}^{-2}$ under the $\lambda>520 \mathrm{~nm}$ light irradiation.

The results provide that the SPR of the Au nanoparticle plays an important role in improving the PEC performance through harvesting more sunlight. 

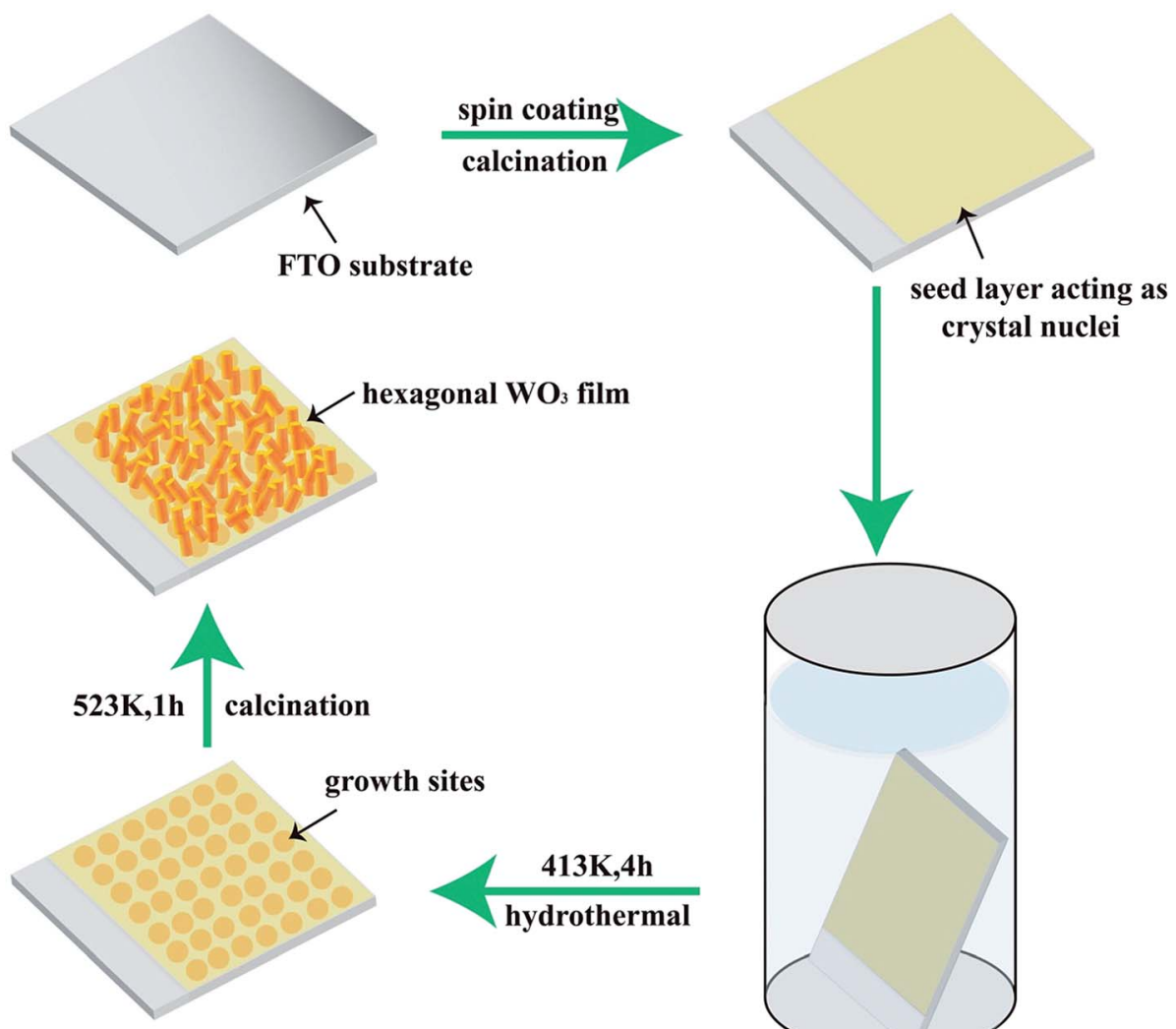

Fig. 3 Schematic of the formation mechanism for the as-prepared $\mathrm{WO}_{3}$ film.
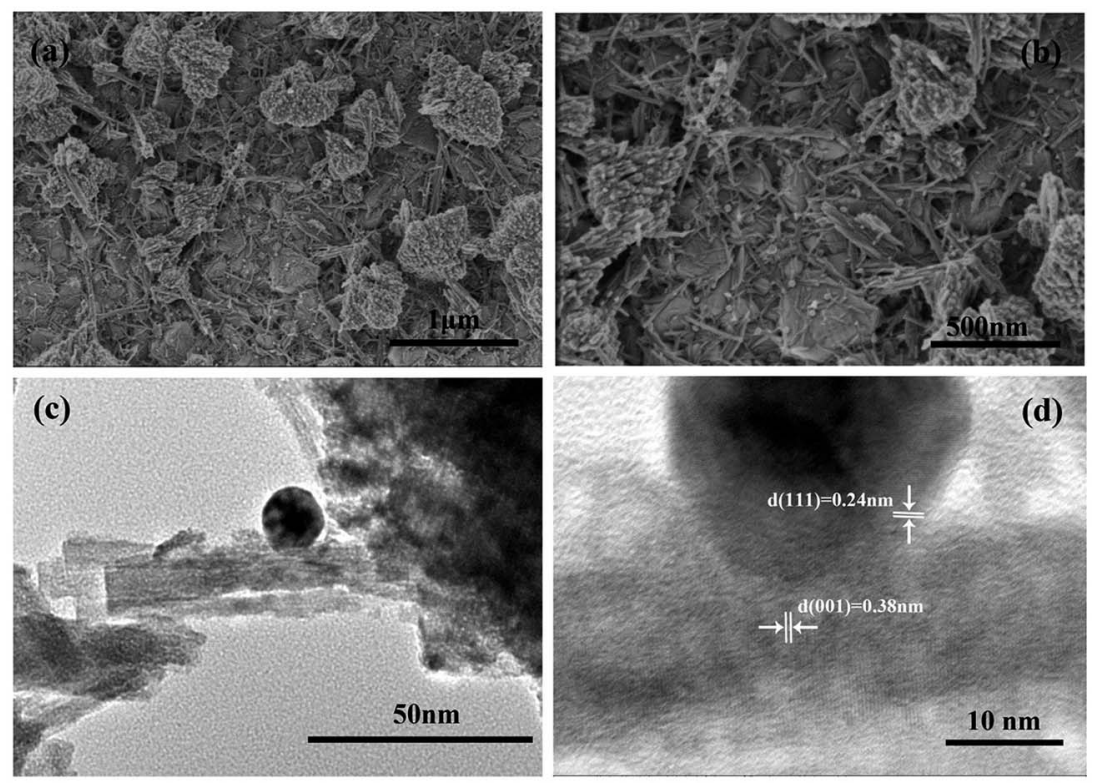

Fig. 4 ( $a$ and b) SEM images and (c and d) HRTEM image for the $\mathrm{Au} / \mathrm{WO}_{3}-1 \mathrm{~h}$ sample.

We next emphasized the shape changes of the photocurrent curve. As shown in Fig. 6a and b, the photocurrent densities of the bare $\mathrm{WO}_{3}$ photoelectrode increased over time during each circulation. This characteristic is attributed to the continuous accumulation of the photoexcited electrons on the surface of the electrode, which originates from the weak reducibility of the $\mathrm{WO}_{3}$ semiconductor. ${ }^{50}$ However, for the $\mathrm{Au} / \mathrm{WO}_{3}-X$ photoelectrodes, the photocurrent curves became square, and the 

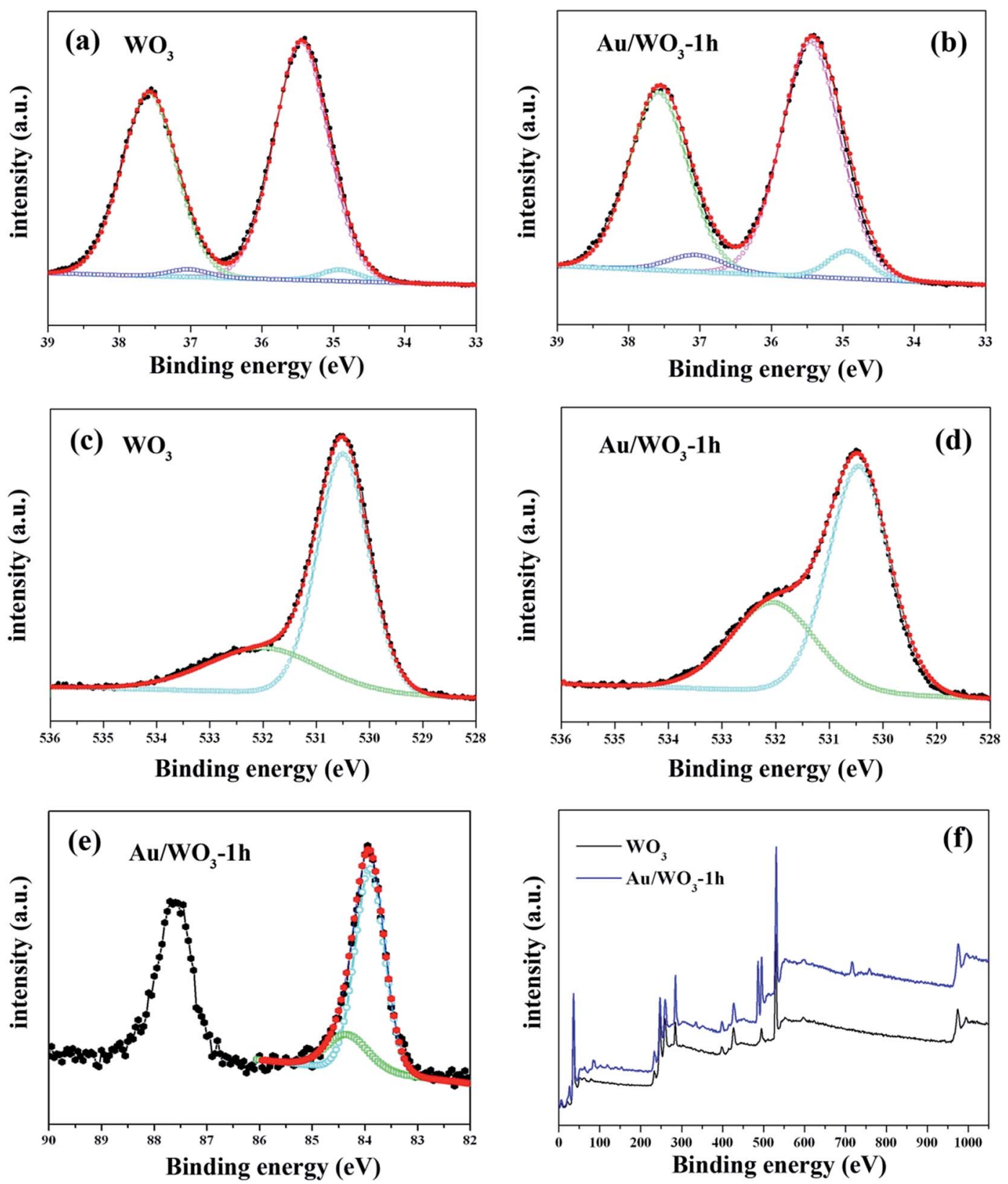

Fig. 5 X-ray photoelectron spectra of region scans of (a and b) W4f, (c and d) O1s, (e) Au4f, and (f) the whole survey scans for the bare $\mathrm{WO}_{3}$ and $\mathrm{Au} / \mathrm{WO}_{3}-1 \mathrm{~h}$ samples.

Table 1 The ratios of $\mathrm{Au} / \mathrm{W}, \mathrm{W}^{5+} / \mathrm{W}^{6+}$ and $\mathrm{Au}^{+} / \mathrm{Au}$ measured from XPS analysis

\begin{tabular}{lllllll}
\hline $\mathrm{Au} / \mathrm{WO}_{3}-X$ & 0 & $15 \mathrm{~min}$ & $30 \mathrm{~min}$ & $1 \mathrm{~h}$ & $2 \mathrm{~h}$ & $4 \mathrm{~h}$ \\
\hline $\mathrm{Au} / \mathrm{W}(\%)$ & - & 0.52 & 0.84 & 1.73 & 2.45 & 3.68 \\
$\mathrm{~W}^{5+} / \mathrm{W}^{6+}(\%)$ & 3.24 & 4.35 & 6.14 & 8.39 & 9.16 & 9.98 \\
$\mathrm{Au}^{+} / \mathrm{Au}(\%)$ & - & 0.32 & 0.57 & 0.75 & 0.94 & 1.21
\end{tabular}

steady-state photocurrents were quickly reached with increasing cyclic times, where the generating and consuming of the photoexcited electrons levelled off. The result implies that $\mathrm{Au}$ nanoparticles improved the reducibility of the $\mathrm{WO}_{3}$ semiconductor and promoted the reduction reactions on the electrode surface. In addition, a remarkable decay of the photocurrent curve was observed for the initial light-on stage in the $\mathrm{Au} / \mathrm{WO}_{3}-X$ photoelectrodes, and the effect was augmented with increasing $\mathrm{Au}$ amounts. The observation indicates that the electron-hole recombination process is present at the surface of photoelectrodes before achieving steady-state photocurrents. ${ }^{5}$ One of the reasons for the recombination is due to the reduction of the initially adsorbed $\mathrm{O}_{2}$ on the $\mathrm{WO}_{3}$ surface by the photoexcited electrons with improved reducibility; another reason should be the compensation of the initial holes accumulated at the $\mathrm{Au} / \mathrm{WO}_{3}$ interface, as discussed with the XPS analysis. Therefore, although the SPR effect of the Au nanoparticles could 

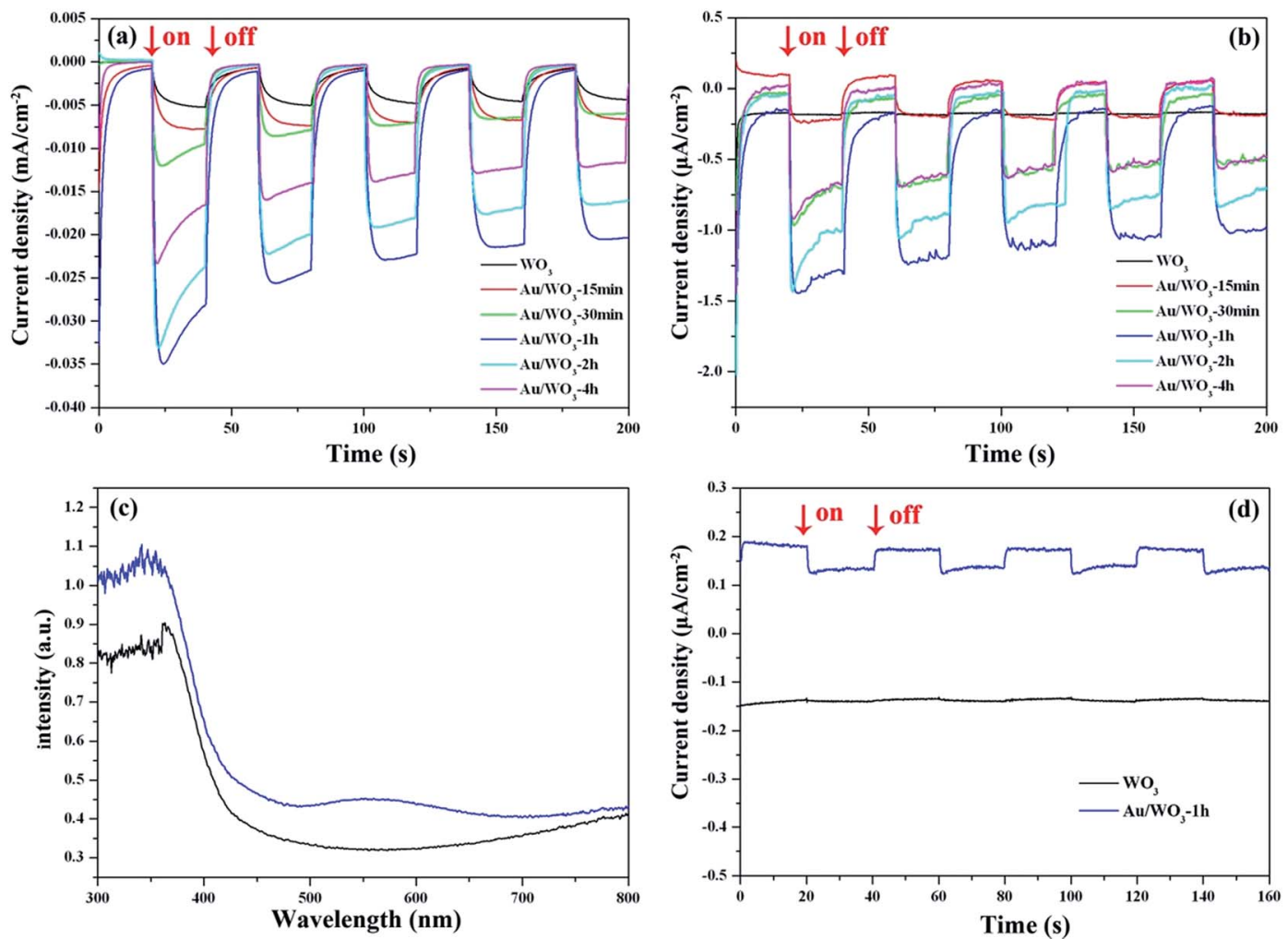

Fig. 6 Photocurrent response of $\mathrm{WO}_{3}$ and $\mathrm{Au} / \mathrm{WO}_{3}-\mathrm{X}$ samples (a) under simulated sunlight irradiation, and (b) under visible light ( $\lambda>420 \mathrm{~nm}$ ) irradiation. (c) UV-Vis diffuse reflectance spectra, and (d) photocurrent response with $\lambda>520 \mathrm{~nm}$ light irradiation of the bare $\mathrm{WO}_{3}$ and $\mathrm{Au} / \mathrm{WO}_{3}-$ $1 \mathrm{~h}$ samples.

Table 2 The PEC performance for bare $\mathrm{WO}_{3}$ and $\mathrm{Au} / \mathrm{WO}_{3}-\mathrm{X}$ electrodes

\begin{tabular}{|c|c|c|c|c|c|c|c|}
\hline \multirow[t]{2}{*}{ Photocurrent densities $\left(\mu \mathrm{A} \mathrm{cm}^{-2}\right)$} & Sunlight & 5.1 & 6.6 & 6.7 & 21.7 & 16.5 & 12.2 \\
\hline & Visible light & 0.02 & 0.2 & 0.5 & 1.1 & 0.8 & 0.6 \\
\hline$R_{\mathrm{ct}}(\mathrm{ohm})$ & & 5537 & 5083 & 4521 & 2164 & 3661 & 5485 \\
\hline \multirow[t]{2}{*}{ IPCE (\%) } & $350 \mathrm{~nm}$ & 10.81 & 19.14 & 24.83 & 35.79 & 26.99 & 21.67 \\
\hline & $420 \mathrm{~nm}$ & 0.39 & 1.07 & 2.07 & 3.51 & 1.57 & 1.16 \\
\hline
\end{tabular}

expand the light response region of photoelectrodes, the modification should be carefully evaluated due to the losses of surface recombination.

In the present study, Mott-Schottky measurements for the bare $\mathrm{WO}_{3}$ and $\mathrm{Au} / \mathrm{WO}_{3}-X$ electrodes in the dark were conducted to investigate the influence of the $\mathrm{Au}$ nanoparticles on the $\mathrm{WO}_{3}$ electronic properties. As shown in Fig. $7 \mathrm{a}$, all $\mathrm{WO}_{3}$ electrodes showed a positive slope in the Mott-Schottky plots, as expected for an n-type semiconductor. The flat band potential $\left(V_{\mathrm{fb}}\right)$ of the bare $\mathrm{WO}_{3}$ electrode was $0.26 \mathrm{eV}$ versus $\mathrm{Ag} / \mathrm{AgCl}$. For the $\mathrm{Au} / \mathrm{WO}_{3}$ $X$ electrodes, this value was shifted to the negative direction. For comparison, the $V_{\mathrm{fb}}$ values were converted to go against a reversible hydrogen electrode (RHE) according to the Nernst equation $^{51}$ as follows:

$$
E_{\mathrm{RHE}}(\mathrm{V})=E_{\mathrm{Ag} / \mathrm{AgCl}}+[0.059(\mathrm{~V}) \times \mathrm{pH}]+E_{\mathrm{Ag} / \mathrm{AgCl}}^{0}(0.194 \mathrm{~V})
$$

The standardized flat band potentials were $0.78,0.57,0.53$, $0.50,0.46$ and $0.42 \mathrm{eV}$ for the bare $\mathrm{WO}_{3}$ and $\mathrm{Au} / \mathrm{WO}_{3}-X$ electrodes, respectively. The decreasing of the $V_{\mathrm{fb}}$ is related to the negative shift of the Fermi level of the electrodes, which is due to electronic accumulation on the $\mathrm{WO}_{3} .{ }^{52} \mathrm{DFT}$ calculations were employed to analyze the electronic transfer process at the $\mathrm{Au} /$ $\mathrm{WO}_{3}$ interface. Fig. 8a and b present the optimized structures of the bare $\mathrm{WO}_{3}$ and $\mathrm{Au} / \mathrm{WO}_{3}(010)$ surfaces. The two strong $\mathrm{O}-\mathrm{Au}$ bonds were formed with 2.147 and $2.139 \AA$ lengths, and the surface $\mathrm{O}-\mathrm{W}$ bonds were elongated from $1.708 \AA$ to $1.812 \AA$. The elongated bonds indicate that the surface $\mathrm{O}$ were activated by the adjacent $\mathrm{Au}$, which agreed with the changes of O1s core level in the XPS analysis. Fig. 8c gives the electron density difference map at the $\mathrm{Au} / \mathrm{WO}_{3}$ interface. It could be seen that some electrons of the $\mathrm{Au}$ are captured by the adjacent surface $\mathrm{O}$ ions, which causes a decrease in the work function of the $\mathrm{WO}_{3}$ 

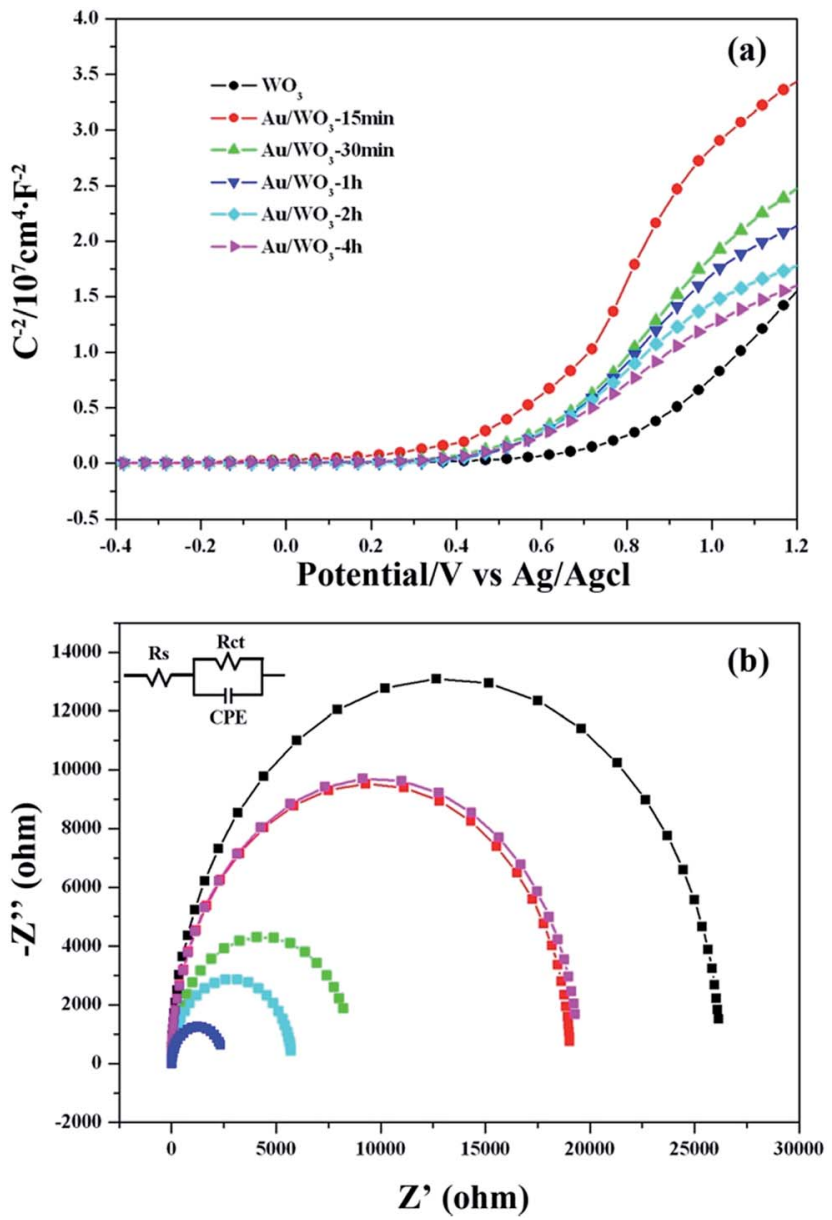

Fig. 7 (a) Mott-Schottky plot and (b) electrochemical impedance spectroscopy Nyquist plots of $\mathrm{WO}_{3}$ and $\mathrm{Au} / \mathrm{WO}_{3}-\mathrm{X}$ samples.

surface from $7.32 \mathrm{eV}$ to $6.90 \mathrm{eV}$. That is, the strong interaction of the $\mathrm{Au}$ and the surface $\mathrm{O}$ at the $\mathrm{Au} / \mathrm{WO}_{3}$ interface is responsible for the negative shift of the Fermi level observed in the MottSchottky measurements. Importantly, the shift tendency with more Au loading was also observed by theoretical calculations, as shown in Fig. S4. $\dagger$ Therefore, we conclude that an inner electric field at the $\mathrm{Au} / \mathrm{WO}_{3}$ interface with direction from $\mathrm{Au}$ to $\mathrm{WO}_{3}$ was built through the electron transfer process. The introduction of the inner electric field will promote the separation of the photoexcited electron-hole at the $\mathrm{Au} / \mathrm{WO}_{3}$ interface, which is one of the reasons for the enhanced photocurrent density. To better understand the dynamics of electronic migration in the $\mathrm{Au} / \mathrm{WO}_{3}$ photoelectrodes, the electrochemical impedance spectroscopy (EIS) measurements were conducted, and the results are shown in Fig. 7b. The semicircle in each Nyquist plot can be fitted using an equivalent circuit containing a series resistance $\left(R_{\mathrm{s}}\right)$, a charge transfer resistance $\left(R_{\mathrm{ct}}\right)$ and a constant phase element (CPE). The EIS results gave a smaller charge transfer resistance (5083, 4521, 2164, 3661 and 5485 ohm) for the $\mathrm{Au} / \mathrm{WO}_{3}-X$ photoelectrodes compared with the 5537 for the bare $\mathrm{WO}_{3}$ photoelectrode. The result again confirms the present and effect of the inner electric field at the $\mathrm{Au} / \mathrm{WO}_{3}$ interface. Note that further increasing the amount of

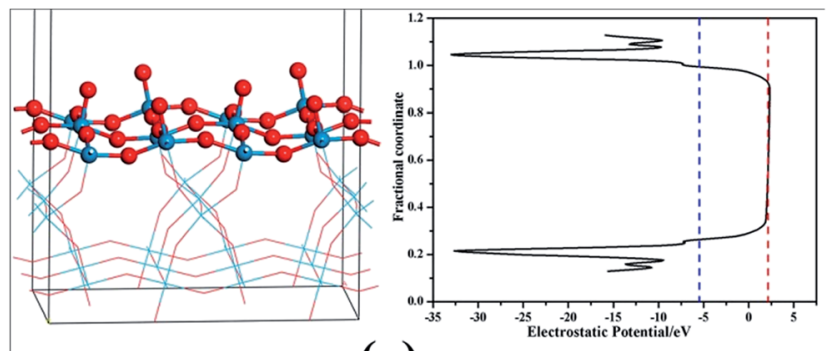

(a)

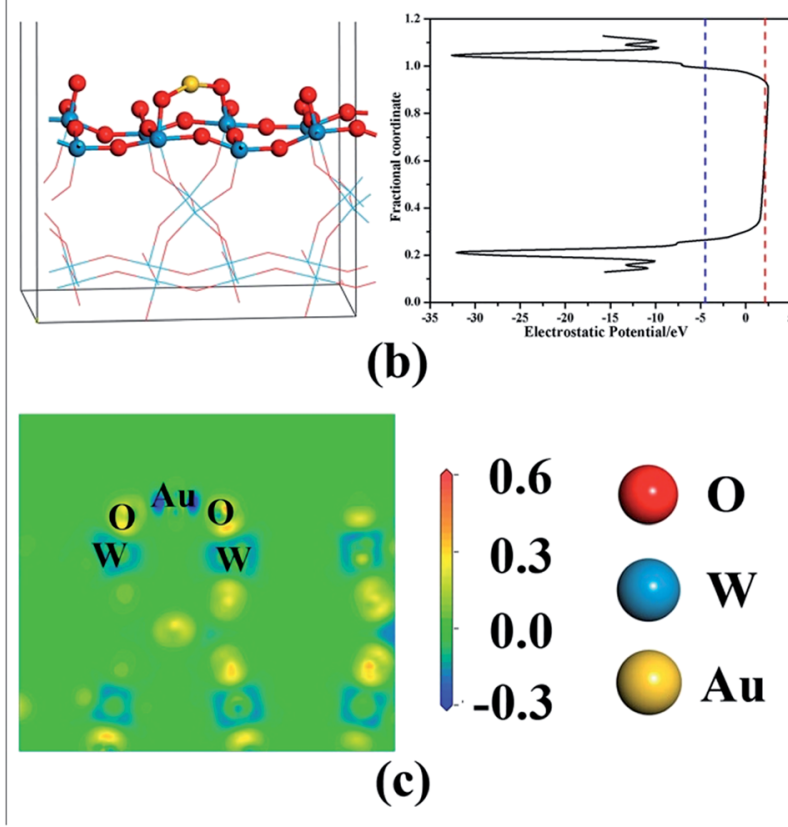

Fig. 8 The structures and the potentials for (a) the bare $\mathrm{WO}_{3}$ and (b) the $\mathrm{Au} / \mathrm{WO}_{3}$ surfaces, and (c) the electron different density map at the $\mathrm{Au} / \mathrm{WO}_{3}$ interface. The blue and red dashed lines represent the Fermi and vacuum levels, respectively.

Au nanoparticles did not further improve electronic transport in the $\mathrm{Au} / \mathrm{WO}_{3}-2 \mathrm{~h}$ and $-4 \mathrm{~h}$ photoelectrodes. This characteristic is in accordance with the result of the photocurrents, which is attributed to the effect of the surface/interface recombination process induced by the Au nanoparticles.

The incident-photon-to-current-conversion efficiency (IPCE) spectra were collected to elucidate the contribution of the loaded $\mathrm{Au}$ nanoparticles. The IPCE values at specific wavelengths were calculated as follows: ${ }^{6}$

$$
\mathrm{IPCE}=(1240 I) /\left(\lambda J_{\text {light }}\right)
$$

where $I$ is the photocurrent density $\left(\mathrm{mA} \mathrm{cm}{ }^{-2}\right), J_{\text {light }}$ is the measured incident light irradiance $\left(\mathrm{mW} \mathrm{cm}^{-2}\right)$ at a specific wavelength, and $\lambda$ incident light wavelength (nm). As shown in Fig. 9a, all $\mathrm{Au} / \mathrm{WO}_{3}-X$ photoelectrodes exhibited a higher IPCE value compared to the bare $\mathrm{WO}_{3}$ photoelectrode in the 350$420 \mathrm{~nm}$ region. The measured IPCE values are summarized in Table 2, which shows the maximum IPCE of $36.3 \%$ for the $\mathrm{Au} /$ $\mathrm{WO}_{3}-1 \mathrm{~h}$ photoelectrode with $350 \mathrm{~nm}$ incident light. It is worth noting that $\mathrm{Au} / \mathrm{WO}_{3}-X$ photoelectrodes have IPCE peaks at $\lambda>$ 


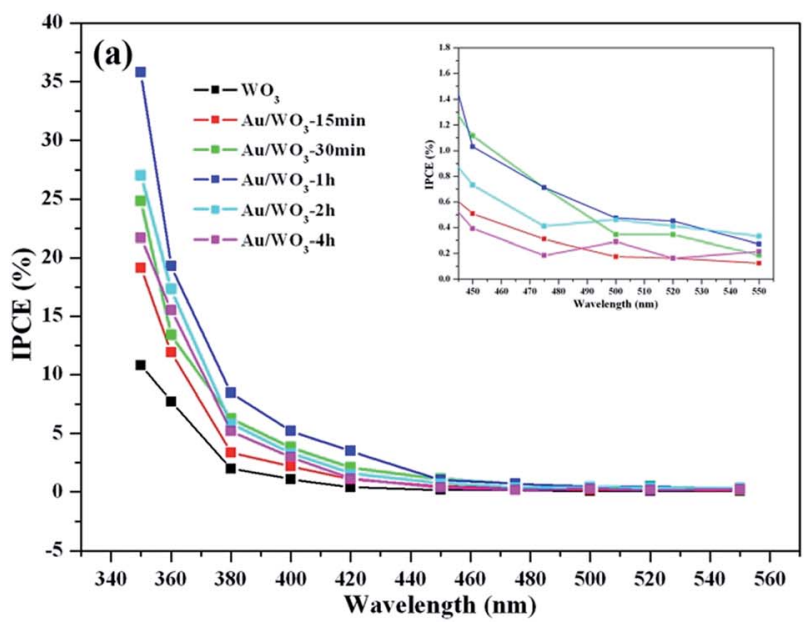

(b)

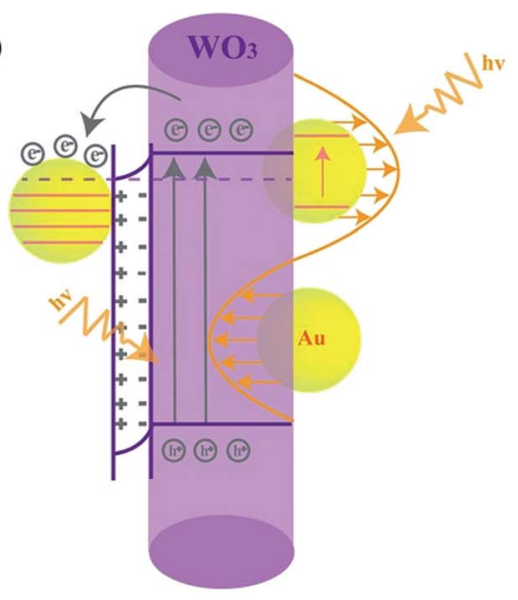

Fig. 9 (a) IPCE plots of the $\mathrm{WO}_{3}$ and $\mathrm{Au} / \mathrm{WO}_{3}-\mathrm{X}$ samples in $0.5 \mathrm{M} \mathrm{Na} \mathrm{SO}_{4}$ aqueous solution under illumination, and (b) proposed mechanism of the bifunctional Au nanoparticles under simulated sunlight irradiation.

$500 \mathrm{~nm}$, which is in good agreement with the SPR absorption of the $\mathrm{Au}$ nanoparticles. Based on the above discussions, two positive effects of the Au nanoparticles are proposed to improve the PEC performance of the $\mathrm{WO}_{3}$ photoelectrode, as presented in Fig. 9b. One is the SPR effect of the Au nanoparticles to harvest more solar energy and the other is the formation of the inner electric field at the $\mathrm{Au} / \mathrm{WO}_{3}$ interface to promote electronhole separation. However, increased recombined centers are also introduced by the Au nanoparticles. Therefore, the loaded amount of the $\mathrm{Au}$ nanoparticles must be balanced to maximize the quantum efficiency of the $\mathrm{Au} / \mathrm{WO}_{3}$ system.

\section{Conclusion}

In the present study $\mathrm{WO}_{3}$ films were prepared by the hydrothermal method, and then the Au nanoparticles were loaded through an immersion method. The 10-20 nm Au nanoparticles showed a significant surface plasmon resonance, which induced the light adsorption at around $560 \mathrm{~nm}$ wavelength. The Mott-Schottky measurements and theoretical calculations indicated that an inner electric field is built at the $\mathrm{Au} / \mathrm{WO}_{3}$ interface, which will promote separation of the photo-excited electron-hole pairs. The synergistic effect of SPR and the inner electric field improve the PEC performance of the $\mathrm{Au} / \mathrm{WO}_{3}$ photoelectrodes. However, we also noted that the loading quantity for the Au nanoparticles should be carefully considered due to introduction of the recombined centers. The present study proposes bifunctional $\mathrm{Au}$ nanoparticles to improve the PEC performance of the $\mathrm{WO}_{3}$ photoelectrode, and provides a basic understanding to construct metal/ semiconductor systems.

\section{Acknowledgements}

This study is supported by the National Natural Science Foundation of China (Grant No. 51402169), and the Shandong Provincial Natural Science Foundation, China (Grant No. ZR2014BP005). The numerical calculations in this study were carried out on the supercomputing system in the Supercomputing Center, Shandong University, Weihai.

\section{References}

1 R. Abe, J. Photochem. Photobiol., C, 2010, 11, 179-209.

2 Y. J. Hwang, C. Hahn, B. Liu and P. D. Yang, ACS Nano, 2012, 6, 5060-5069.

3 L. Li, Y. Yu, F. Meng, Y. Tan, R. J. Hamers and S. Jin, Nano Lett., 2012, 12, 724-731.

4 G. Wang, H. Wang, Y. Ling, Y. Tang, X. Yang, R. C. Fitzmorris, C. Wang, J. Z. Zhang and Y. Li, Nano Lett., 2011, 11, 3026-3033.

5 D. K. Zhong, S. Choi and D. R. Gamelin, J. Am. Chem. Soc., 2011, 133, 18370-18377.

6 M. G. Ahmed, T. A. Kandiel, A. Y. Ahmed, I. Kretschmer, F. Rashwan and D. Bahnemann, J. Phys. Chem. C, 2015, 119, 5864-5871.

7 M. Barroso, S. R. Pendlebury, A. J. Cowan and J. R. Durrant, Chem. Sci., 2013, 4, 2724.

8 A. Kargar, Y. Jing, S. J. Kim, C. T. Riley, X. Q. Pan and D. L. Wang, ACS Nano, 2013, 7, 11112-11120.

9 M. T. Mayer, C. Du and D. Wang, J. Am. Chem. Soc., 2012, 134, 12406-12409.

10 K. Sivula, F. Le Formal and M. Gratzel, ChemSusChem, 2011, 4, 432-449.

11 X. Y. Yang, A. Wolcott, G. M. Wang, A. Sobo, R. C. Fitzmorris, F. Qian, J. Z. Zhang and Y. Li, Nano Lett., 2009, 9, 2331-2336.

12 J.-R. Ding and K.-S. Kim, AIChE J., 2016, 62, 421-428.

13 H. Li, G. Shi, H. Wang, Q. Zhang and Y. Li, J. Mater. Chem. A, 2014, 2, 11305.

14 J. Yang, W. Li, J. Li, D. Sun and Q. Chen, J. Mater. Chem., 2012, 22, 17744.

15 Y. Yang, R. Xie, Y. Liu, J. Li and W. Li, Catalysts, 2015, 5, 2024-2038.

16 M. Ma, K. Zhang, P. Li, M. S. Jung, M. J. Jeong and J. H. Park, Angew. Chem., Int. Ed., 2016, 55, 11819-11823. 
17 S. C. Wang, H. J. Chen, G. P. Gao, T. Butburee, M. Q. Lyu, S. Thaweesak, J. H. Yun, A. J. Du, G. Liu and L. Z. Wang, Nano Energy, 2016, 24, 94-102.

18 H. I. Kim, J. Kim, W. Kim and W. Choi, J. Phys. Chem. C, 2011, 115, 9797-9805.

19 C. W. Lai, S. Sreekantan, E. Pei San and W. Krengvirat, Electrochim. Acta, 2012, 77, 128-136.

20 S. L. Liew, Z. Zhang, T. W. G. Goh, G. S. Subramanian, H. L. D. Seng, T. S. A. Hor, H. K. Luo and D. Z. Chi, Int. J. Hydrogen Energy, 2014, 39, 4291-4298.

21 Y. Y. Liu, Y. Li, W. Z. Li, S. Han and C. J. Liu, Appl. Surf. Sci., 2012, 258, 5038-5045.

22 T. Zhu, M. N. Chong and E. S. Chan, ChemSusChem, 2014, 7, 2974-2997.

23 T. Zhang, Z. Zhu, H. Chen, Y. Bai, S. Xiao, X. Zheng, Q. Xue and S. Yang, Nanoscale, 2015, 7, 2933-2940.

24 K. C. Leonard, K. M. Nam, H. C. Lee, S. H. Kang, H. S. Park and A. J. Bard, J. Phys. Chem. C, 2013, 117, 15901-15910.

25 X. B. Chen, S. H. Shen, L. J. Guo and S. S. Mao, Chem. Rev., 2010, 110, 6503-6570.

26 N. Bao, L. Shen, T. Takata and K. Domen, Chem. Mater., 2008, 20, 110-117.

27 S. S. K. Ma, K. Maeda, R. Abe and K. Domen, Energy Environ. Sci., 2012, 5, 8390-8397.

28 K. Maeda and K. Domen, J. Phys. Chem. Lett., 2010, 1, 26552661.

29 M. Ni, M. K. H. Leung, D. Y. C. Leung and K. Sumathy, Renewable Sustainable Energy Rev., 2007, 11, 401-425.

30 J. H. Yang, D. G. Wang, H. X. Han and C. Li, Acc. Chem. Res., 2013, 46, 1900-1909.

31 D. B. Ingram and S. Linic, J. Am. Chem. Soc., 2011, 133, 52025205.

32 A. Primo, T. Marino, A. Corma, R. Molinari and H. Garcia, J. Am. Chem. Soc., 2011, 133, 6930-6933.

33 J. Li, S. K. Cushing, P. Zheng, T. Senty, F. Meng, A. D. Bristow, A. Manivannan and N. Wu, J. Am. Chem. Soc., 2014, 136, 8438-8449.

34 F. Xu, Y. Yao, D. Bai, R. Xu, J. Mei, D. Wu, Z. Gao and K. Jiang, J. Colloid Interface Sci., 2015, 458, 194-199.
35 J. Zhu, X. Huo, X. Liu and H. Ju, ACS Appl. Mater. Interfaces, 2016, 8, 341-349.

36 J. H. Yang, H. J. Yan, X. L. Wang, F. Y. Wen, Z. J. Wang, D. Y. Fan, J. Y. Shi and C. Li, J. Catal., 2012, 290, 151-157.

37 Y. C. Pu, G. Wang, K. D. Chang, Y. Ling, Y. K. Lin, B. C. Fitzmorris, C. M. Liu, X. Lu, Y. Tong, J. Z. Zhang, Y. J. Hsu and Y. Li, Nano Lett., 2013, 13, 3817-3823.

38 Y. Kong, H. Sun, X. Zhao, B. Gao and W. Fan, Appl. Catal., A, 2015, 505, 447-455.

39 L. Wang, J. Zhan, W. Fan, G. Cui, H. Sun, L. Zhuo, X. Zhao and B. Tang, Chem. Commun., 2010, 46, 8833.

40 R. Azimirad, O. Akhavan and A. Z. Moshfegh, J. Phys. Chem. C, 2009, 113, 13098-13102.

41 N. Naseri, R. Azimirad, O. Akhavan and A. Z. Moshfegh, Thin Solid Films, 2010, 518, 2250-2257.

42 Y. Baek and K. Yong, J. Phys. Chem. C, 2007, 111, 1213-1218.

43 F. Peng, L. F. Cai, H. Yu, H. J. Wang and J. Yang, J. Solid State Chem., 2008, 181, 130-136.

44 Y. Wang, C. X. Feng, M. Zhang, J. J. Yang and Z. J. Zhang, Appl. Catal., B, 2010, 100, 84-90.

45 N. Naseri, M. Amiri and A. Z. Moshfegh, J. Phys. D: Appl. Phys., 2010, 43, 105405-105413.

46 D. D. Du, W. J. Li, S. S. Chen, T. J. Yan, J. M. You and D. S. Kong, New J. Chem., 2015, 39, 3129-3136.

47 S. J. Hong, H. Jun, P. H. Borse and J. S. Lee, Int. J. Hydrogen Energy, 2009, 34, 3234-3242.

48 J. T. Li, S. K. Cushing, J. Bright, F. K. Meng, T. R. Senty, P. Zheng, A. D. Bristow and N. Q. Wu, ACS Catal., 2013, 3, 47-51.

49 Y. C. Pu, G. M. Wang, K. D. Chang, Y. C. Ling, Y. K. Lin, B. C. Fitzmorris, C. M. Liu, X. H. Lu, Y. X. Tong, J. Z. Zhang, Y. J. Hsu and Y. Li, Nano Lett., 2013, 13, 38173823.

50 Y. Liu, C. S. Xie, J. Li, T. Zou and D. W. Zeng, Appl. Catal., A, 2012, 433, 81-87.

51 S. Ikeda, N. Sugiyama, B. Pal, G. Marci, L. Palmisano, H. Noguchi, K. Uosaki and B. Ohtani, Phys. Chem. Chem. Phys., 2001, 3, 267-273.

52 V. Subramanian, E. E. Wolf and P. V. Kamat, J. Am. Chem. Soc., 2004, 126, 4943-4950. 